DOI 10.37882/2500-3682.2021.11.03

\title{
СУЩНОСТЬ И ПСИХОЛОГИЧЕКИЕ ПРИЧИНЫ ПРОСТРАНСТВЕННОЙ МОБИЛЬНОСТИ
}

\section{SPATIAL MOBILITY: A SOCIETY OF CHANGE}

\section{N. Zabolotny}

Summary: One of the key conditions for the psychological, economic and social development of the state and its individual subjects is the demographic situation: the quantitative and qualitative composition of the population. These indicators are determined by the action of a single law for any society, which is based on the conformity of the economy, social and demographic development, as well as a psychological sense of comfort. According to this rule, there is a stable relationship between the movement of the quantity, quality of the state of the population and the volume of development of psychological, economic and social areas. The article considers spatial mobility as a variant of migration of the population subject to psychological pressure, touches on the psychological adaptation of migrants and problems arising against the background of negative factors and slow adaptation to the modern social environment, which affect the personal state and vision.

Keywords: psychology of migration, spatial mobility, personal mobility, psychological adaptation, migration flows, forced migration.

\author{
Заболотный Николай Васильевич \\ Соискатель, Московский государственный \\ университет имени М.В. Ломоносова, \\ nsabolotnij@googlemail.com
}

Аннотация: Одним из ключевых условий психологического, экономического и социального развития государства и его отдельных субъектов является демографическая ситуация: количественный и качественный состав населения. Эти показатели определяются действием единого для любого общества закона, который держится на соответствии экономики, социального и демографического развития, а также психологического ощущения комфорта. Согласно этому правилу, между движением количества, качества состояния населения и объёмом развития психологической, экономической и социальной областей существует стойкая взаимосвязь.

В статье рассматривается пространственная мобильность как вариант миграций населения, подверженного психологическому давлению, затрагивается психологическая адаптация мигрантов и проблемы, возникающие на фоне негативные факторов и медленной адаптации к современной социальной среде, которые влияют на личностное состояние и видение.

Ключевые слова: психология миграций, пространственная мобильность, мобильность личности, психологическая адаптация, миграционные потоки, вынужденная миграция.
B последние десятилетия наша среда обитания прогрессирует быстрее, чем развиваются психологические качества адаптации личности, такие как социальная мобильность. Само понятие мобильности предполагает приспосабливание к новой, быстро развивающейся среде. В психологии это понятие недостаточно изучено, и в прошлые годы практически не привлекало исследователей. Однако недавние исследования интеллекта человека, выявили зависимость пространственной мобильности от социальной составляющей.

В современном мире при быстром развитии экономических процессов и ускоренном освоении новых знаний изучение способности приспосабливаться оказывается весьма актуальным навыком.

В настоящее время личностная пространственная мобильность является важным качеством меняющегося современного мира, несомненно, необходимым и презентабельным, позволяющим человеку, в процессе совершенствования, вписаться в круговорот научно-технологической революции [1, с.150].

Характеристика мобильности интерпретируется как умение быстро переходить, привыкать, адаптироваться к современным условиям.

В психологии выделяют следующие виды пространственной мобильности: восходящая, нисходящая, социальная, образовательная. Еще в своей книге «Человек. Цивилизации. Общество» П.А. Сорокин характеризовал социальную пространственную мобильность как переход модификации человеческой деятельности и из одного состояние в другое, доказывая в утверждениях важность и значимость пространственной мобильности личности.

Пространственная мобильность представляет собой своеобразный процесс развития, что Н. Постмен отмечал в одной из своих работ, помимо этого он впервые ввел понятие «диалог культуры с собой», что подразумевает, в том числе, пространственную мобильность как один из факторов развития личности человека.

Мобильная личность можно охарактеризовать как личность чувственную к сторонним воздействиям, открытую к взаимодействию с другими личностями в социальной среде, находящуюся в диалоге с собой, но при этом способную к своевременным трансформациям, конверсиям и эволюции своих действий в соответствии 
с ситуацией [3, с.244]. Вариативность происходит по собственному побуждению индивида, погружая тем самым, в конъектуру, которая его окружает.

Парк Р. изучая данную проблему заметил, что пространственные перемещения взаимозависимы от личных отношений с окружением, трудовых отношений, родственных связей, а выход из зоны комфорты (миграция, смена всего привычного) являются своеобразным ускорителем психологической составляющей пространственной мобильности личности.

Василенко П.В. считал, что пространственная мобильность - это не что иное как выражение миграционных стадий, которые можно рассматривать по миграционной ситуации.

Мктрчан Н.В. изучая пространственную мобильность, отмечал в своих работах, что понимает этот термин как миграции.

П.А. Сорокин и Г. Зиммель рассматривали пространственную мобильность во взаимосвязи с мобильностью психологической и социальной. Мобильные пространственные перемещения рассматривали в своих работах J. Urry и P. Кононенко, А.В. Стрельникова. Конструктивными мнениями в своих подходах к пространственной мобильности отличались В. Вахштайн и Л. Болтански, Л.В. Давыдкина.

Прирост пространственной мобильности стал ярким примером развития современного мира и обуславливается быстрым развитием экономики и прогресса, увеличением скорости смены сверхдолгосрочных циклов, социодемографией, увеличением потока информации и скоростью ее обработки. Уровень пространственной мобильности можно описать, как возможность населе- ния быстро адаптироваться. Значительные масштабы временных перемещений заметны, как правило, в развивающихся странах, диктуемое трансформацией труда $[4$, c.4] при переходе к технологическому кладу.

Таблица 1.

Миграции населения за январь-апрель 2020г. и 2021г.

\begin{tabular}{|l|c|c|c|}
\hline $\begin{array}{l}\text { Прибытие иностранных граж- } \\
\text { дан и лиц без гражданства }\end{array}$ & 22449 & 19579 & $\mathbf{- 2 8 7 0}$ \\
\hline $\begin{array}{l}\text { Иностранные граждане и лица } \\
\text { без гражданства }\end{array}$ & 425666 & 530411 & $\mathbf{1 0 4 7 4 5}$ \\
\hline
\end{tabular}

Составлено автором по данным Росстата [9, с.194].

Данные таблицы 1 и рисунка 1 свидетельствует о прогрессирующем росте миграций населения.

В данном контексте актуальной видится проблема психологической характеристики пространственной мобильности и ее дальнейшего использования в социальной сфере [7].

Мобильность в социуме описана в трудах П.А. Сорокина, характеризуя виды социальной мобильности горизонтальную как перемещение людей в пределах социального слоя и вертикальную как восходящие или нисходящее перемещение [10, с.176].

П.А. Сорокин акцентировал свою работу на горизонтальной мобильности, что привело к тому, что им был упущен такой аспект как географическая мобильность.

В учебнике Ю.В. Яковца и Б.Н. Кузыка «Цивилизации: теория, история, будущее» [10, с.176], описывается общество в древние времена, где существовало разделение на страты, слои, зависящие от биологического начала

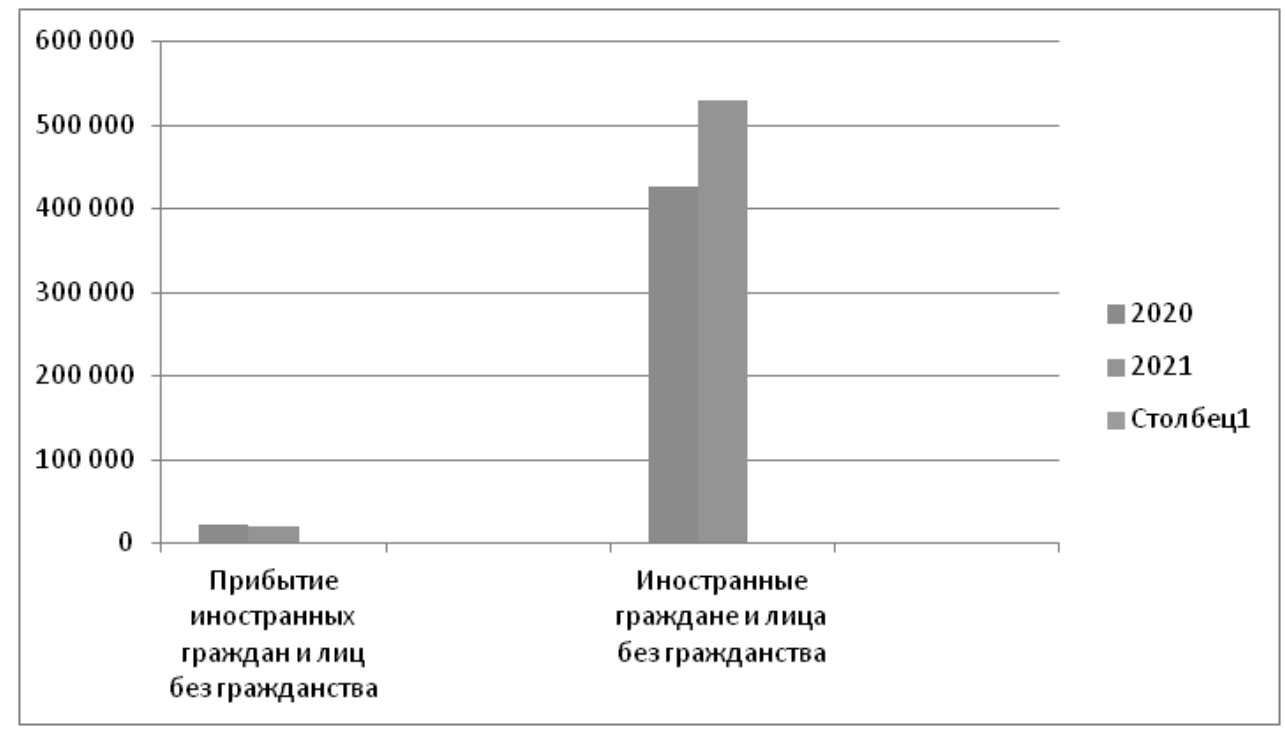

Рис. 1. Статистические данные миграций (январь-апрель 2020 г. и 2021 г.) 
человека и в том числе, от его положения в социуме. Исключение составляло только движение в социуме, в рамках социальной мобильности и характеризовалась П.А. Сорокиным как стратификация. Позднее им же были введены такие понятия как социальные координаты (отношение к группе людей), социальная стратификация (классификация по имущественному, профессиональному и политическому признакам), социальная мобильность (иерархическая система перемещения человека в социуме).

Социальная мобильность как таковая возникла еще во времена становления неолитической цивилизации, а точнее появилась в одно время с социальной стратификацией (период возникновения общественного разделения труда) в Древнем Египте. Уже тогда существовало множество профессий (скульпторы, певцы, писцы, садовники и прочее) и существовали социальные институты, такие как армия, суд [8, с.47]. Примерно в ту же эпоху сложилась индийская цивилизация, широко известная своим кастовым режимом и отсутствием возможности перехода из одной касты в другую. А в середине I тыс. н. э. разрушение античного общества привело к ускоренному процессу мобильности (время завоеваний - рабы и феодалы, цари, короли, церкви, крестьяне, возникновение социальных групп - таких как ремесленники, художники, артисты и прочее). Все это только укрепило социальную мобильность в обществе. На протяжении длительного периода в истории прослеживается социальная мобильность, но только в начале 21 века цивилизационный кризис привел к взрыву социальной мобильности и преобразованиям ней, что можно охарактеризовать как возрождение религии, попытки смягчение политической и имущественной пропасти и активизации социальной мобильности людей (потоки мигрантов). Наряду с обычной социальной миграцией населения существует вынужденная миграция, которая является скорее необходимостью, чем личным выбором.

Изменения в обществе, в частности увеличение количества постигаемой информации, социальную дистанцию, финансовые потоки новой величины, увеличение ритма и скорости жизни предугадал в своих трудах Г. Зиммель. Им была очень точно описана современная модель жизни в человека, модель «чужака» (человека без дома и страны).

Ускоренное расширение и увеличение количества дорожных магистралей привело к мобильности людей в пространстве, как и предписывал в своих работах Дж. Урри.

Одним из методов изучения пространственной мобильности является конструктивистский подход, который является междисциплинарным и позволяет рассматривать мобильность по нескольким научным направлениям. Основой такого отношения к рассмотре- нию и изучению фактов и процессов в социальной среде является коммуникация и идеи. Идеи используются как правило, инструментальным методом для легитимации/ делегитимации, задействовав материальные мотивы.

Интерпретативный метод строится на понимании и объяснении конструктивизма, который подразумевает невозможность отказа от трактовки реальности, поэтому такой подход видится распознания идеи и ее направления, что целесообразно, если учитывать социальные факторы.

В исследуемой проблематике нужно различать строгое придерживание правил и более мягкий подход в позициях ученых-конструктивистов. Одни самостоятельны, другие - наоборот, рассматривают все решения и направления действий в совокупности с идеями, и никогда отдельно.

Отсюда можно предположить, что существуют факторы социума, оказывающие влияние на пространственную мобильность с психологической точки зрения[2, с. 67]. К ним относятся:

- рынок труда, напрямую зависящий от состояния экономики, что провоцирует мобильность граждан в поисках работы;

- стратификация общества, являющаяся полным противопоставлением кастам, общинам и сословия; стратификация возможно лишь в свободном обществе как проявление личной воли;

- возрастные особенности, как правило, значительно сокращают возможности для пространственной мобильности; подвержены этому факторы почти все: возраст, наличие детей, причем чем выше место на кадровой ступени, тем больше вероятность, что отсутствуют наследники или их минимальное количество, и наоборот.

- миграция и целеустремленность выходцев из селений, как правило всегда выше, чем имеющих достойное положение в обществе горожан.

- влияние образования, уравнивает шансы разности социальных слоев и дает возможности для продвижения по карьерной лестнице;

- интеллект и хорошие базовые физические данные, способствуют лучшей адаптации в обществе и значительно помогают в поисках места в социуме.

На основании опыта выдающихся умов в науке найдены и отражены факторы, от которых зависят все проявления социальной пространственной мобильности, обоснована взаимосвязь мобильности и миграций, причины перехода вертикальной мобильности общества к пространственной мобильности. При этом личность может изменять свои психологические характеристики, находясь в состоянии пространственной мобильности. 
Таким образом, быстро меняющаяся внешняя среда создает условия, в которых в центре политики организации труда находиться человек, который психологически ощущает себя в социуме только при приемлемых условиях труда и жизни, из которых и строится жизнедеятельность современного общества.

\section{ЛИТЕРАТУРА}

1. Гониева А.О. Современные тенденции и проблемы международной миграции рабочей силы / А.О. Гониева // Индустрия туризма: возможности, приоритеты, проблемы и перспективы. 2019. Т. 14. № 2. 150-157 с.

2. Жантлисова Е.А. Зарубежный опыт регулирования международной миграции рабочей силы: возможности применения в России / Е.А. Жантлисова, 0.Н. Чеботарева // Наука и производство Урала, 2019. Т. 15. 67-68 с.

3. Иванюхина Д.А. Международная миграция рабочей силы: преимущества и недостатки / Д.А. Иванюхина // Вестник современных исследований, 2018. № 11.8 (26). 244-246 c.

4. Миграция рабочей силы, ее причины и виды [Электронный ресурc]: URL: https://spravochnick.ru/ Щербакова Е.М. Международная миграция, 2017 / Е.М. Щербакова // Демоскоп Weekly, 2017. № 753-754. 4 c.

5. Миркина 0.Н. Тенденции современной международной миграции рабочей силы / 0.Н. Миркина // Экономический журнал, 2018. № 3 (51). $92-107$ с.

6. Нустойчивость занятости. Международный и российский контексты будущего сферы труда: Монография/под ред. Бобкова В.Н. М.: Изд-во РеалПринт, 2017. 35 c.

7. Официальный сайт Федеральной службы государственной статистики РФ [Электронный ресурc] URL: http://www.gks.ru.

8. Панькин П.В. Миграционное воздействие на рынок труда России / П.В. Панькин // Экономика и бизнес: теория и практика. — 2020. 一 № 11-2. 47-49 С.

9. Российский статистический ежегодник. М.: Росстат, 2017. 194 с.

10. Яковец Ю.В. Научная революция XXI века-фундаментальная основа прогресса цивилизаций //Партнерство цивилизаций. - 2013. - №. 1-2. 176-185 с.

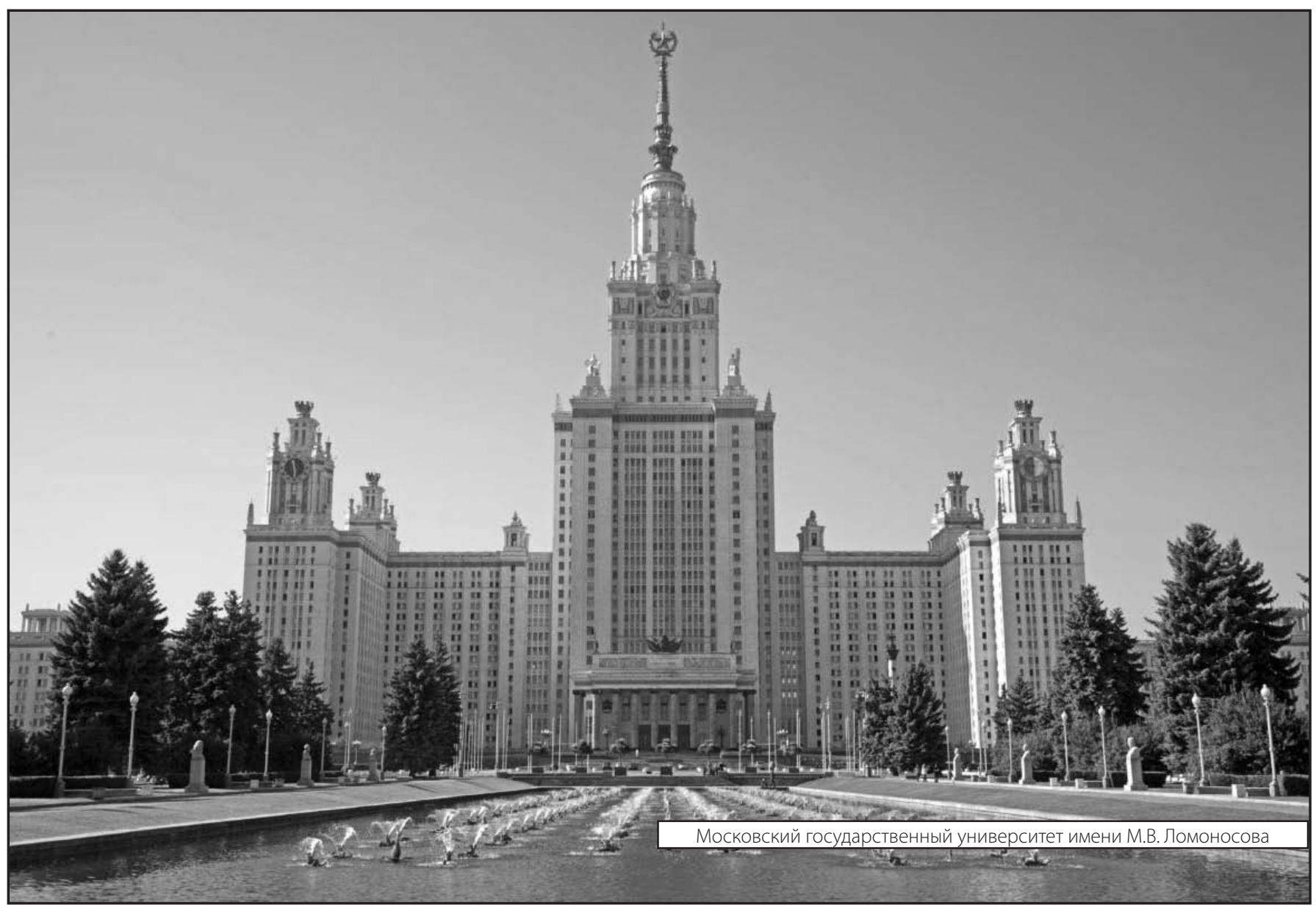

